\title{
Cost and clinical consequences of smoking cessation in outpatients after cardiovascular disease: a retrospective cohort study
}

This article was published in the following Dove Press journal:

ClinicoEconomics and Outcomes Research

17 August 2013

Number of times this article has been viewed

\author{
Antoni Sicras-Mainar' \\ Silvia Díaz-Cerezo 2 \\ Verónica Sanz de Burgoa ${ }^{3}$ \\ Ruth Navarro-Artieda ${ }^{4}$ \\ 'Directorate of Planning, Badalona \\ Serveis Assistencials SA, Badalona, \\ Spain; ${ }^{2}$ Health Economics and \\ Outcomes Research Department, \\ Pfizer, SLU, Alcobendas, Spain; ${ }^{3}$ Medical \\ Department, Pfizer, SLU, Alcobendas, \\ Spain; ${ }^{4}$ Medical Documentation \\ Unit, Hospital Germans Trias i Pujol, \\ Badalona, Spain
}

\begin{abstract}
This cohort retrospective study explored the cost and clinical consequences of smoking cessation in outpatients after cardiovascular events (CVEs), in Spain. A total of 2,540 patients (68.1 years; $60.7 \%$ male; $8.4 \%$ smokers, $52.9 \%$ ex-smokers, and $38.7 \%$ never smokers) fulfilling the selection criteria and followed up throughout a period of 36 months after the event were considered eligible for analysis. Total costs were higher among current smokers in comparison with ex-smokers and never smokers (€7,981 versus [vs] €7,322 and €5,619, respectively) ( $P<0.001)$. Both health care costs $(€ 6,273$ vs $€ 5,673$ and $€ 4,823$, respectively) $(P<0.001)$ and loss of productivity at work costs $(€ 1,708$ vs $€ 1,650$ and $€ 796$, respectively $)$ $(P<0.001)$ accounted for such differences. There was also a difference in CVE recurrence rates (18.6\% vs $16.5 \%$ and $9.6 \%$, respectively) $(P<0.01)$. Smoking cessation in CVE outpatients was associated with lower cost and risk of CVE recurrence compared with smokers, and their health status was similar to that of never smokers, in routine clinical practice in Spain.
\end{abstract}

Keywords: mortality, health resources, health care costs

\section{Introduction}

Smoking is considered to be a chronic, addictive disease and is the single main cause of preventable morbidity and mortality in developed countries. ${ }^{1}$ It is an established etiological factor for many respiratory and cardiovascular diseases and cancer, and frequently causes these conditions to become acute again. ${ }^{2,3}$ The mortality attributable to smoking has begun to decline; however, it still constitutes a major public health problem requiring a multidisciplinary approach. It is estimated that one in four deaths in men and one in every 40 in women can be attributed to smoking, in the general Spanish population. ${ }^{4,5}$ In Spain, the prevalence of smoking among patients with acute myocardial infarction is $35 \%$ and around $32 \%$ in patients with angina. In general, it has been calculated that $29 \%$ of the deaths due to coronary disease are due to smoking and that one in every three deaths caused by smoking is premature. ${ }^{6,7}$ Various studies have shown a correlation between the number of cigarettes smoked (dose-response) and the number of arteries affected, to the extent that the relative risk is close to 5.5 for fatal cardiovascular episodes in smoking patients in comparison with never smokers. ${ }^{8}$ Smoking is also an independent risk factor for hemorrhagic and thrombotic cerebrovascular accidents (CVAs), with a risk between 1.4 and 5.7 times higher than that for people who have never smoked. ${ }^{9}$ In addition, peripheral vascular disease (PVD) occurs two to five times more in smokers than in never smokers, so smoking is considered to be the most important risk factor for the development of peripheral vascular disease. ${ }^{10}$
Correspondence: Antoni Sicras-Mainar Dirección de Planificación y Desarrollo Organizativo, C Gaietà Soler, 6-8 entlo, 089I I Badalona, Barcelona, Spain

Tel +34935072684

Email asicras@bsa.cat 
Smoking cessation is accompanied by a reduction in cardiovascular risk. ${ }^{11}$ In patients with heart disease who stop smoking, a decrease in the incidence of coronary events and a reduction in the symptoms of arteriosclerotic disease have been observed. However, the study by van Berkel showed that $49 \%$ of coronary patients who were initially smokers continued to smoke or had relapsed within 3 months of an acute coronary syndrome. ${ }^{11}$

The involvement of all health care professionals at the various levels of health care is valuable for the management of smoking cessation. ${ }^{7,12,13}$ There is very little or no evidence available regarding the impact of smoking on resource utilization and the costs associated with a subsequent cardiovascular event (CVE). The goal of this study was to determine the effect of smoking cessation on the use of health care and non-health care resources and the associated costs in patients who have experienced a CVE, under conditions of routine medical practice in a given population.

\section{Methods}

\section{Study design and population}

A multicentre, observational, cohort design was used, starting with a retrospective review of the medical records (included in a computerized database) of outpatients and patients admitted to hospital. The study population comprised individuals assigned to six primary health care centers (HCCs) managed by the health provider Badalona Serveis Assistencials SA. Resource-use information was obtained from two reference hospital centers: the Hospital Municipal de Badalona and the Hospital Germans Trías i Pujol, Badalona, Spain. The study included all patients seeking health care between January 1, 2003 and December 31, 2007 who met the following criteria: (a) over 30 years of age; (b) patients who had had a first confirmed CVE with hospital admission (between 2003 and 2007); (c) adherent to the treatment protocol for cardiovascular risk established at the center; (d) in the chronic prescriptions program, (e) regularly attended their scheduled follow-up appointments; and (f) had records of their smoking habit. Subjects were excluded if they: were transferred to another HCC, died as a result of the first CVE, or were transient visitors to the area. In addition, those patients who changed their smoking status (smoker, ex-smoker, or never smokers) between the 3 months after the event until the completion of the study period were also excluded. Possible changes in smoking habits during the first 3 months after the CVE were not taken into account, as these may have been due solely to the fact that the patient was in a hospital setting. Patient follow up after the date of onset of the CVE was 36 months ( 3 years) for the main metrics (biochemistry parameters, prevalence of subsequent CVEs, and health care and non-health care costs).

The records were kept confidential as required by the Spanish Personal Data (Protection) Act (Fundamental Law 15 of December 13, 1999) by using dissociated data. The study was classified by the Spanish Medicines and Health Care Products Agency as a postmarketing observational study and was subsequently approved by the Clinical Research Ethics Committee of Germans Trías i Pujol University Hospital.

\section{Metrics for smoking and CVEs}

Smoking status (smoker or "consistent smokers," ex-smoker or "consistent ex-smokers" [defined as a minimum of 1 year without smoking], and never smokers or "consistent never smokers") prior to the CVE was established according to the definitions accepted by the scientific community. ${ }^{1,13}$ The CVEs recorded were ischemic cardiomyopathy (angina pectoris including ischemic cardiomyopathy, and acute myocardial infarction) and cerebrovascular disease (stroke, transient ischemic attack or PVD), according to the International Classification of Diseases, Clinical Modification (ICD9-CM) ${ }^{14}$ and/or the International Classification for Primary Care (ICPC-2). ${ }^{14}$

During the 3-year follow-up period, all new CVE episodes were recorded. These included cardiac ischemia, both stable (code K74) and unstable (K76), and acute myocardial infarction (K75). Also recorded, were stroke (ischemic, hemorrhagic, and/or transient stroke; K90, K91, and K93), transient ischemic attack (K93), and PVD (all types). The classification of events was obtained from the discharge reports from specialist care and/or from referral to ICPC-2. The cumulative incidence rate was defined as the proportion of individuals developing a new CVE. The results were not standardized, as the population pyramid distributed by age and sex of the study patients was similar to that of the population of Catalonia. Death was recorded during patient follow up (mortality for any reason).

\section{Sociodemographic and comorbidity variables}

The main study variables were: age (continuous and by ranges) and sex, as well as the personal history obtained from ICPC-2, including all possible comorbidities (with their respective ICPC-2 codes). As a summary variable for general comorbidity, we calculated the Charlson Index (severity $)^{15}$ 
for each patient, and the range of health care resource usage bands (RUBs) alongside individual case histories were obtained from the adjusted clinical groups (ACG). ${ }^{16}$

\section{Health care resource utilization and costs included in the analysis}

Two types of costs were analyzed: direct health care costs and indirect costs (average for patient), from a social perspective. Direct costs were considered to be those related to requests for diagnoses and treatment. The different outpatient components of the study were: laboratory tests (blood count, biochemistry, serology, or microbiology), standard radiology and diagnostic tests (endoscopy, electromyography, computed tomography scans, magnetic resonance imaging, stress tests, echocardiography, etc). Costs for the various types of personnel, consumables, and outsourced structural services were considered fixed costs. Using this procedure (intermediate product), a mean cost was calculated for each visit completed (primary, specialist, and emergency) and for each day of hospitalization. The days of hospitalization were classified as medical or associated with a diagnostic/ treatment procedure (ICD-9-CM classification), and a mean cost per stay was obtained using distribution criteria. Outpatient medication (medical prescriptions related to the CVE) was assessed according to the retail sales price at the time when the prescription was written. The indirect costs included were those relating to losses of productivity in the workplace (number of sick leave days and days off work). The cost was quantified by the mean interprofessional wage scale published by the Spanish National Statistics Institute. ${ }^{17}$ The costs were determined throughout the 3 years of follow up for each patient.

\section{Statistical analysis}

A univariate descriptive statistical analysis was performed using mean values, standard deviation (SD), and 95\% confidence intervals (CI); the normality of the distribution was confirmed with the Kolmogorov-Smirnov test. In the bivariate analysis, Student's $t$ test, analysis of variance (ANOVA), Chi squared test, Pearson's linear correlation, and the Mann-Whitney-Wilcoxon nonparametric test were all used. The median times of CVE incidence were estimated by means of a Kaplan-Meier survival analysis, and the levels of significance between the groups were established using the Mantel-Cox logrank statistic. A logarithmic regression analysis was performed with a forward step procedure (Wald statistic) to adjust for factors associated with smoking. The comparison of the outpatient and hospital cost was made according to the recommendations of Thompson and Barber, ${ }^{18}$ using an analysis of covariance (ANCOVA), with sex, age, the Charlson index, and the RUBs as covariables. SPSS for Windows, Version 17 software (SPSS Inc, Chicago, IL, USA) was used, and statistical significance was established for a value of $P<0.05$.

\section{Results}

From an initial selection of 52,372 subjects over 30 years of age assigned to and regularly seen at the HCCs, a total of 2,540 patients were recruited (Figure 1). Excluding losses, $19.1 \%$ of the smokers continued smoking after a first CVE. Ex-smokers and never smokers mostly remained so after their first CVE, with less than 1\% taking up smoking again or starting to smoke after this event. The final study sample comprised 213 smokers (8.4\%), 1,344 ex-smokers (52.9\%), and 983 never smokers (38.7\%), after excluding the losses and the patients who had changed their smoking habit. The mean time as a smoker was 24.4 (SD 14.5) years and as an ex-smoker was 14.2 (11.2) years. Table 1 describes the general sociodemographics and clinical characteristics of the sample at baseline. For all subjects studied, the presence of a CVA was $58.8 \%$ and of ischemic cardiomyopathy $41.2 \%$; whereas, in the smokers group, it was $67.6 \%$ and $32.4 \%$, respectively $(P=0.019)$.

After 3 years of follow up, the mortality from all causes (including intrahospital and follow-up periods) was $4.2 \%(3.4 \%-5.0 \%)$; among smokers, the mortality was $4.2 \%(1.5 \%-6.9 \%)$, whereas among ex-smokers, it was $5.9 \%(4.6 \%-7.2 \%)$ and among never smokers, it was $1.8 \%$ (1.1\%-2.6\%). The median CVE death-free survival time was 26.7 (22.6-30.7) weeks: 24.8 (11.1-38.5) weeks in smokers, 23.8 (18.1-29.4) in ex-smokers, and 34.5 (22.7-42.4) in never smokers. The comparison between groups, using the logrank test, was as follows: (a) smokers versus ex-smokers: $P=0.654$; (b) smokers versus never smokers: $P=0.042$; and (c) ex-smokers versus never smokers: $P=0.528$. The incidence of new CVEs was 15.2\% (13.8\%-16.6\%) during the 36 months of follow-up; in smokers, the new-CVE incidence was $18.6 \%(13.4 \%-23.8 \%)$, while in ex-smokers, it was $16.5 \%(14.5 \%-18.5 \%)$, and in never smokers, it was $9.6 \%(9.6 \%-13.6 \%)(P<0.01)$. The incidence rate in smokers was 65.0 cases per 1000 person-years; in ex-smokers, 55.3 cases per 1000 person-years; and in never smokers, 32.1 cases per 1000 person-years. The survival curve for new CVEs is displayed in Figure 2. In the study, most recurrent cardiovascular disease among never smokers and former smokers was observed during the first 


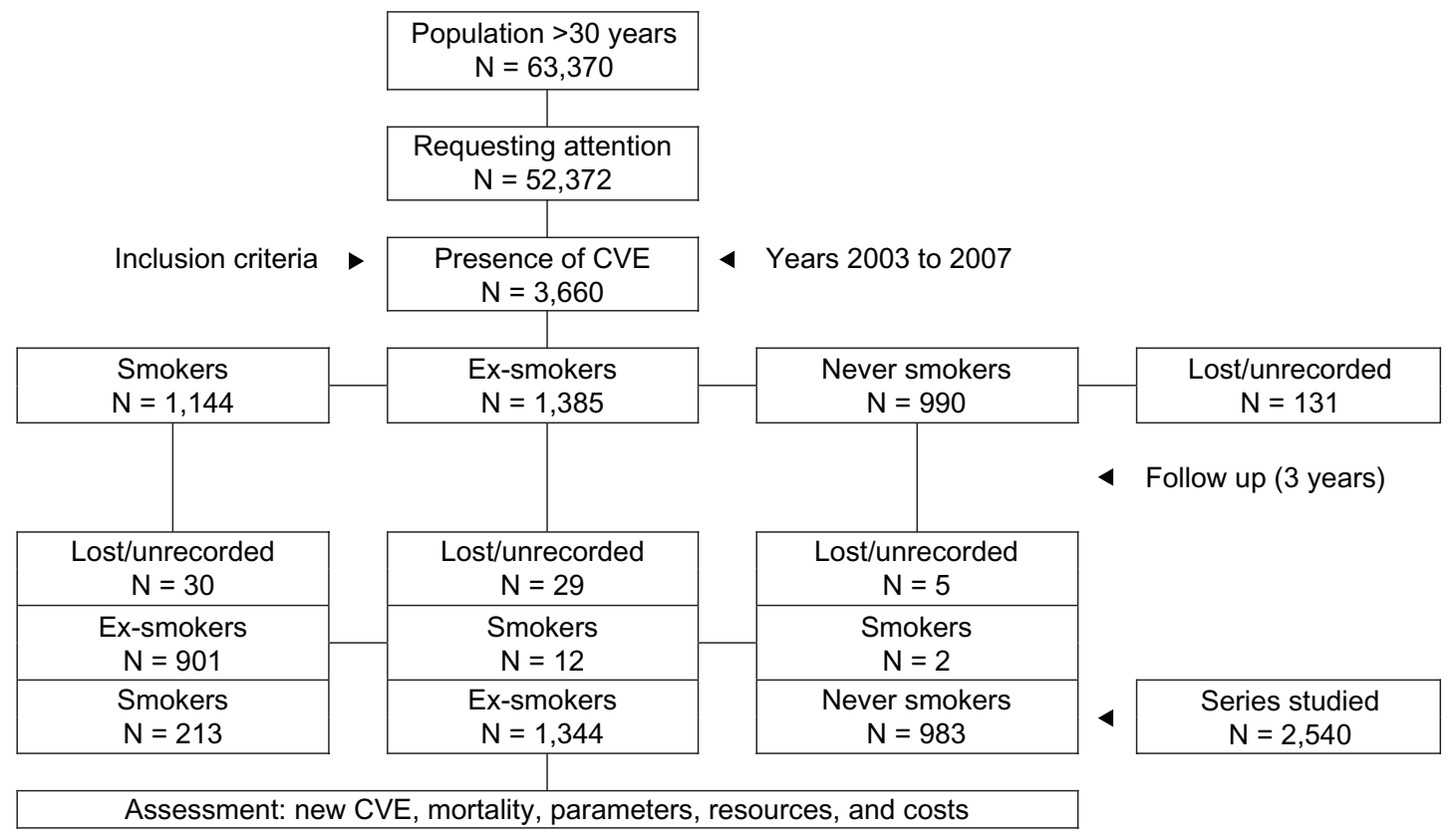

Figure I Patient disposition tree for analysis.

Notes: Retrospective observational design with the goal of determining the effect of consuming tobacco (smokers, ex-smokers, and never smokers) on the use of health and non-health resources and the associated costs, in patients who had suffered some kind of CVE, in routine conditions of clinical practice.

Abbreviation: CVE, cardiovascular event.

year and the third (Figure 2), whereas during the second, the differences observed were not statistically significant $(P>0.05)$. Smokers showed a lower median time to onset of further CVEs: for smokers, this was 80 days, while for ex-smokers, this was 100 days, and for never smokers, this was 200 days $(P<0.03)$. By type of CVE, 9.2\% presented some type of ischemic cardiomyopathy, and $5.8 \%$ had a CVA. Ischemic cardiomyopathy was seen in $10.4 \%$ of smokers, $10.5 \%$ of ex-smokers, and $8.3 \%$ of never smokers (comparison of smokers versus ex-smokers yielded $P>0.05$, while comparison of smokers versus never smokers yielded $P=0.041$ ). CVAs were present in $8.2 \%, 6.0 \%$, and $3.3 \%$, respectively $(P<0.05$ in all cases). Figure 3 shows the incidence of each type of CVE during patient follow up. By study groups, the greatest differences were seen in stroke (4.2\% in smokers, $3.3 \%$ in ex-smokers, and $2.4 \%$ in never smokers $)(P<0.05)$ and in PVD $(2.8 \%$ in smokers, $1.6 \%$ in ex-smokers, and $0.3 \%$ in never smokers $)(P<0.03)$.

Compared with ex-smokers and never smokers, smokers had more HCC medical visits, days in hospital, visits to specialists, and presented the greatest losses in terms of productivity (Table 2). The observed and adjusted costs model, by groups, is shown in Table 3 . The total cost reached 16.2 million Euros, of which 78.4\% corresponded to direct health costs and $21.6 \%$ to non-health costs (loss of productivity), with a mean/unit total of $€ 6,391$. Of the health costs, $50.0 \%$ were produced in HCCs and $28.4 \%$ in specialist care. By groups, the total costs for smokers were higher in comparison with ex-smokers and never smokers $(€ 7,828$ versus $€ 6,832$ and $€ 5,476$, respectively) $(P<0.001)$. After adjusting by confounders, costs were higher among smokers in comparison with ex-smokers and never smokers. Both health care and loss of productivity in the workplace costs accounted for such findings (Table 3).

\section{Discussion}

Although tobacco addiction is a highly prevalent condition (about $26 \%$ of the population are regular smokers) ${ }^{19}$ and there are numerous intervention strategies related to cessation, there have been few studies aimed at assessing the clinical (mortality and cardiovascular morbidity) and economic consequences in patients who have had a CVE, in the context of daily clinical practice. In our study, $19.1 \%$ of the smokers continued smoking after their first CVE. This percentage is lower than the figure found in the literature. This circumstance may be due to the possible impact of the health policies applied recently in our country. Thus, in a meta-analysis of the controlled clinical trials offering standard therapy to patients admitted to hospital for a first CVE, it was seen that the mean percentage of patients continuing to smoke after the event was $66 \%$ in the group treated with standard therapy and 58\% in the group offered 
Table I General characteristics of the series by study group

\begin{tabular}{|c|c|c|c|c|c|}
\hline \multirow{2}{*}{$\frac{\text { Study group }}{\text { Number of patients, } \%}$} & \multirow{2}{*}{$\frac{\text { Smokers }}{N=213(8.4 \%)}$} & \multirow{2}{*}{$\frac{\text { Ex-smokers }}{1,344(52.9 \%)}$} & \multirow{2}{*}{$\frac{\text { Never smokers }}{\mathrm{N}=983(38.7 \%)}$} & \multirow{2}{*}{$\frac{\text { Total }}{N=2,540(100 \%)}$} & \multirow[t]{2}{*}{$P$} \\
\hline & & & & & \\
\hline \multicolumn{6}{|c|}{ Sociodemographic characteristics } \\
\hline Mean age, years & $68.1(11.8)$ & $68.1(14.0)$ & $68.2(12.3)$ & $68.1(13.2)$ & NS \\
\hline Sex (males) & $85.0 \%$ & $63.2 \%$ & $51.7 \%$ & $60.6 \%$ & $<0.001$ \\
\hline Pension regime & $73.2 \%$ & $74.0 \%$ & $85.2 \%$ & $78.3 \%$ & $<0.001$ \\
\hline \multicolumn{6}{|l|}{ Ranges } \\
\hline $3 \mathrm{I}-44$ years & $4.2 \%$ & $5.6 \%$ & $2.7 \%$ & $4.4 \%$ & \\
\hline $45-64$ years & $42.3 \%$ & $28.2 \%$ & $20.2 \%$ & $26.3 \%$ & \\
\hline $65-74$ years & $31.9 \%$ & $26.6 \%$ & $23.2 \%$ & $25.7 \%$ & \\
\hline$>74$ years & $21.6 \%$ & $39.6 \%$ & $53.8 \%$ & $43.6 \%$ & $<0.001$ \\
\hline \multicolumn{6}{|l|}{ General comorbidity } \\
\hline Mean Charlson index & $2.1(1.5)$ & $2.1(1.5)$ & $2.1(1.5)$ & $2.1(1.5)$ & NS \\
\hline Mean RUBs & $2.4(0.9)$ & $2.5(0.9)$ & $2.4(0.9)$ & $2.4(0.9)$ & NS \\
\hline \multicolumn{6}{|l|}{ Associated comorbidities } \\
\hline Arterial hypertension & $56.8 \%$ & $55.8 \%$ & $54.6 \%$ & $55.4 \%$ & NS \\
\hline Diabetes mellitus & $37.6 \%$ & $31.9 \%$ & $32.8 \%$ & $32.7 \%$ & NS \\
\hline Dyslipidemia & $57.7 \%$ & $54.7 \%$ & $54.4 \%$ & $54.8 \%$ & NS \\
\hline Obesity & $26.8 \%$ & $31.8 \%$ & $34.0 \%$ & $32.2 \%$ & NS \\
\hline Heart failure & $18.8 \%$ & $22.8 \%$ & $24.6 \%$ & $23.2 \%$ & NS \\
\hline Bronchial asthma & $2.3 \%$ & $4.5 \%$ & $4.6 \%$ & $4.3 \%$ & NS \\
\hline COPD & $21.1 \%$ & $8.6 \%$ & $6.2 \%$ & $8.7 \%$ & $<0.001$ \\
\hline Neuropathies & $1.4 \%$ & $2.2 \%$ & $1.2 \%$ & $1.8 \%$ & NS \\
\hline Dementias (of all types) & $2.8 \%$ & $4.3 \%$ & $6.6 \%$ & $5.1 \%$ & 0.013 \\
\hline Organic psychosis & $0.9 \%$ & $0.5 \%$ & $0.9 \%$ & $0.7 \%$ & NS \\
\hline Depressive syndrome & $23.0 \%$ & $20.5 \%$ & $20.7 \%$ & $20.7 \%$ & 0.049 \\
\hline Malignant neoplasias & $14.1 \%$ & $10.6 \%$ & $9.4 \%$ & $10.4 \%$ & NS \\
\hline \multicolumn{6}{|c|}{ Prior cardiovascular events } \\
\hline$>I \mathrm{CVE}$ & $8.0 \%$ & $4.3 \%$ & $1.1 \%$ & $5.2 \%$ & $<0.001$ \\
\hline CVE number & I.I (0.3) & I.I (0.4) & $1.0(0.1)$ & I.I (0.3) & $<0.001$ \\
\hline
\end{tabular}

Note: Values expressed as percentage or mean (standard deviation).

Abbreviations: COPD, chronic obstructive pulmonary disease; CVE, cardiovascular event; NS, not significant; RUBs, resource utilization bands; SD, standard deviation.

behavioral therapies. ${ }^{20}$ On the other hand, in a literature review of 19 observational studies carried out between 1975 and 1994 that mostly included patients admitted to hospital for acute myocardial infarction, the mean percentage of patients who continued smoking was $51 \%$ (50\% in the 10-year period between 1975 and 1984, and $58 \%$ between 1985 and 1994). ${ }^{19}$ Chow et al, after analyzing 18,809 patients included in the Organization to Assess Strategies in Acute Ischemic Syndromes (OASIS) clinical trial, concluded that $35 \%$ of patients continued smoking 30 days after the CVE, although after 6 months, $24 \%$ of them had managed to quit smoking. ${ }^{21}$

The incidence of new CVEs was $15.2 \%$, and the mortality for all causes was $4.2 \%$, with a significant difference between smoking and never smoking patients. ${ }^{21}$ The beneficial effect of smoking cessation has been extensively studied, in the reduction of deaths after an infarction, ${ }^{22}$ cardiovascular risk, ${ }^{23}$ and stroke. ${ }^{24}$ Despite the methodological differences, our results are similar to those described in various cohort studies of coronary patients, in whom a $46 \%$ reduction in mortality was seen associated with smoking cessation, ${ }^{2,20,25}$ and to the results of other authors who found a statistically significant reduction in the percentage of reinfarction in patients who quit smoking, at both 5 and 10 years of follow up. ${ }^{21,25,26}$ The persistence of smoking was significantly associated with a recurrence of CVE, threefold higher than in patients who quit smoking. There is no doubt that patients, who continued smoking or who started again after a few months, had a worse prognosis than those who quit smoking. ${ }^{3}$ Globally, smokers have been found to have a threefold increase of myocardial infarction compared with never smokers. ${ }^{27,28}$ It is known that by quitting smoking, the risk of acute myocardial infarction is reduced by 1.5 times after 3 years, although a residual risk remains even 20 years after giving up smoking. ${ }^{29}$ On the other hand, smoking is considered to be a more powerful risk factor for PVD than for coronary disease..$^{30}$ The relation between smoking and PVD has been extensively documented, and the risk does not completely disappear after the patient quits smoking. ${ }^{31,32}$ 


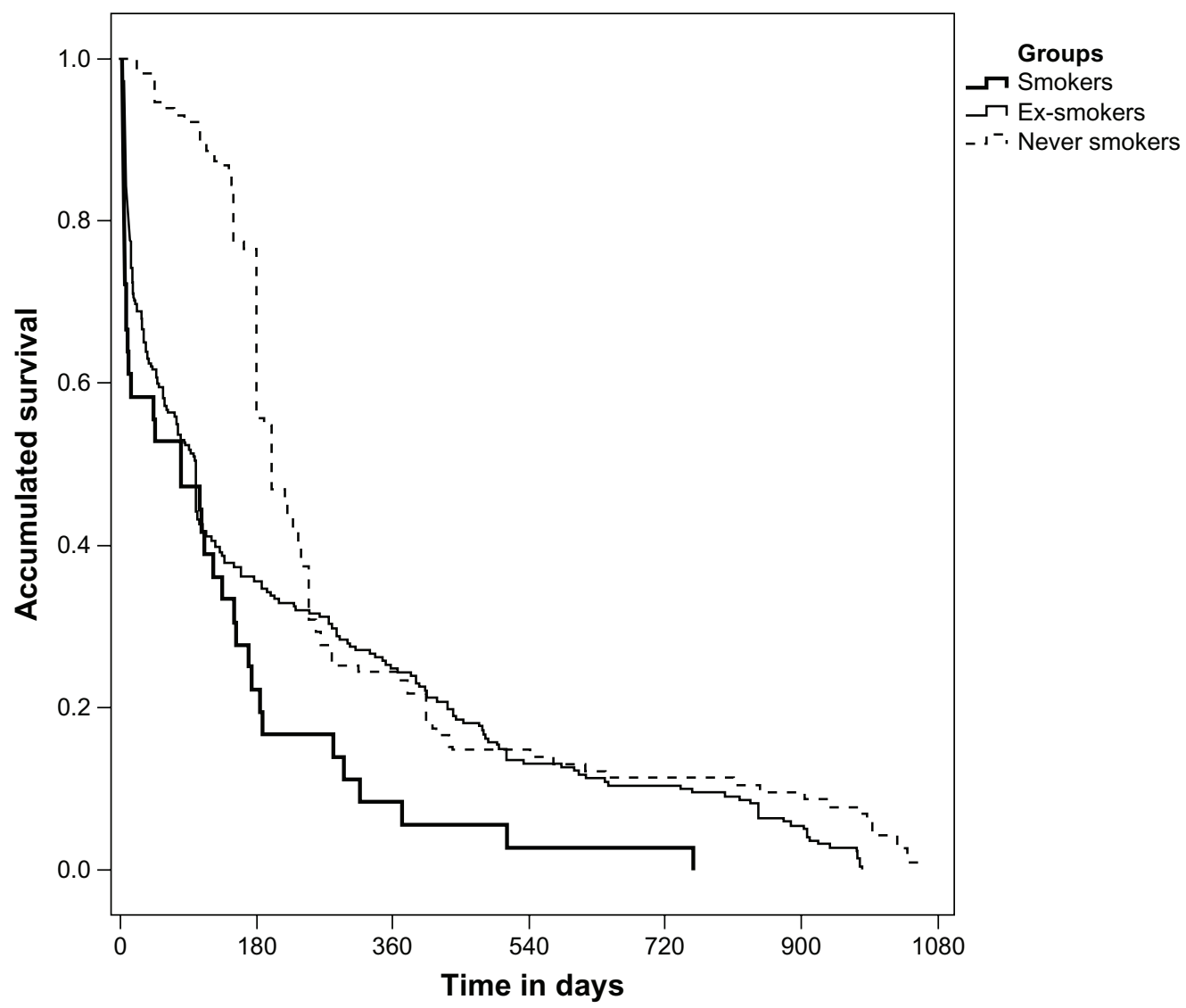

Figure 2 Survival curve for new cardiovascular events during the 36 months of follow up.

Notes: Estimate of the mean times until a new event: in all patients was 237.5 days (95\% Cl: 210.I-265.I); in smokers, was I24.4 days (95\% Cl: $70.8-178.1$ ); in ex-smokers, was 220.8 days ( $95 \%$ Cl: 183.8-257.7); and in never smokers, was 305.3 days (95\% Cl: 256.9-353.6). The Kaplan-Meier curves show estimates of the median time (in days) of patients who had incidence of cardiovascular events during follow up. The incidence of CVEs in the three groups, was I50 days (95\% Cl: I29.I-I7I.2); in smokers, was 80 days ( $95 \%$ Cl: I.3-167.7); in ex-smokers, was 100 days (95\% Cl: 83.8-1 16.2); and in never smokers, was 200 days (95\% Cl: 166.9-233.1). Comparison of curves using the logrank test: comparisons between groups of smokers versus ex-smokers: $P=0.021$; comparisons between groups of smokers versus never smokers: $P<0.00 \mathrm{I}$; comparisons between groups of ex-smokers versus never smokers: $P<0.001$.

Abbreviations: $\mathrm{Cl}$, confidence interval; $\mathrm{CVE}$, cardiovascular event.

On the other hand, costs were higher among smokers in comparison with ex-smokers and never smokers, for health-related costs and lost productivity in the workplace, respectively. These data are one of the strengths of this paper, in view of the difficulty of finding such information in the literature. As for the distribution of the total cost of caring for patients, $78 \%$ came from direct health costs: $28 \%$ from specialist care and $50 \%$ from HCCs. These results are difficult to interpret due to the paucity of available data, although this is precisely what makes them particularly interesting. Compared with another study using a similar methodology $\mathrm{y}^{33}$ costs were high, particularly due to the readmissions to hospital among smokers and/or their high morbidity. The minimal costs in work-related disability generated by smoking in general are worth noting. A possible explanation is that the patients had a high mean age, placing most of them outside the active labor market.
With these data, the importance of smoking cessation seems evident, as does the need for more aggressive interventions for secondary prevention, as recommended by the scientific societies. ${ }^{13}$ Caring for patients with chronic diseases, such as smoking, should be based on care provided by multidisciplinary teams, with the aim of promoting, from all possible angles, effective interventions that ensure patients are involved in their self-care. In general, medium- and low-income countries do not have well-developed smokingmonitoring policies, whereas high-income countries with a higher educational level have developed better national-level policies. The data from the INTERHEART study ${ }^{29}$ refer to the world-wide intensification of smoking-monitoring policies. In Spain, it is possible that the results of our study may change with the new Government measurements against smoking, due to a reduction in exposure to tobacco smoke and perhaps to a decrease in tobacco consumption among smokers. It would be interesting to analyze the data in the years to come, 


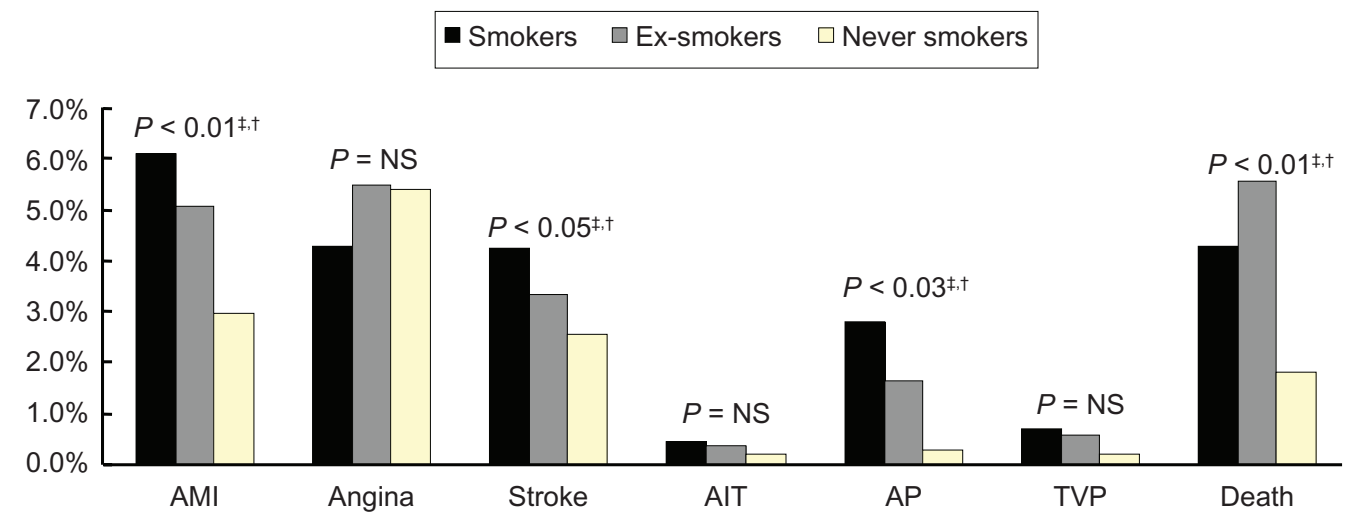

Figure 3 Accumulated incidence of CVEs and mortality during the 3 years of follow up.

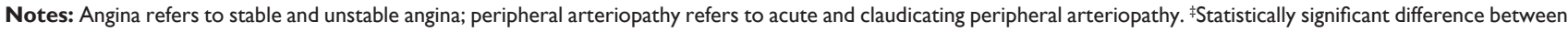
smokers and ex-smokers; †'statistically significant difference between smokers and never smokers.

Abbreviations: AMI, acute myocardial infarction; stroke (hemorrhagic or ischemic); AIT, transient ischemic attack; AP, peripheral arteriopathy; CVEs, cardiovascular events; NS, not significant; TVP, deep vein thrombosis.

in order to be able to assess how the associated costs decrease in keeping with the prevalence of tobacco use.

The possible limitations of the study consist of the disease categorization, a possible bias in patient classification, the metrics for smoking status, and the operational metric for costs, attributable to the information system used. The results of the study could have been modified by some confounding variable that has not been measured. It is known that some smokers deny their smoking, and that the proportion is higher for those advised by their doctor to quit following a CVE. In the group of smokers, compared with ex-smokers and never smokers, there was a higher proportion of losses to follow up. The study also did not consider the costs associated with patient death, and this should be considered as a limitation of the study. Furthermore, the lack of randomization of the groups as well as the lack of data on consumption (the number and type of cigarettes), and the length of time as an ex-smoker could be confounding factors in the comparison between the groups. This study has some of the limitations inherent in retrospective observational studies, such as underreporting of disease and possible variability among professionals and patients.

In conclusion, the results of this study show how smoking patients, in comparison with ex-smokers and never smokers, in routine clinical practice, continue to run a high risk of future CVEs, thus representing a high cost for the health system.

\section{Acknowledgments}

The authors wish to thank Javier Rejas for reviewing the manuscript and for his valuable comments and suggestions regarding the final version of the manuscript.

Table 2 Utilization of health care and non health care resources by study groups

\begin{tabular}{|c|c|c|c|c|c|c|c|c|c|}
\hline \multirow{3}{*}{$\begin{array}{l}\text { Study groups } \\
\text { Number of patients, } \%\end{array}$} & \multirow{2}{*}{\multicolumn{2}{|c|}{$\begin{array}{l}\text { Smoker } \\
N=213(8.4 \%)\end{array}$}} & \multirow{2}{*}{\multicolumn{2}{|c|}{$\begin{array}{l}\text { Ex-smoker } \\
1,344(52.9 \%) \\
\end{array}$}} & \multirow{2}{*}{\multicolumn{2}{|c|}{$\begin{array}{l}\text { Never smokers } \\
N=983(38.7 \%)\end{array}$}} & \multirow{2}{*}{\multicolumn{2}{|c|}{$\begin{array}{l}\text { Total } \\
\mathrm{N}=2,540(100.0 \%)\end{array}$}} & \multirow[t]{3}{*}{$P$} \\
\hline & & & & & & & & & \\
\hline & Use (\%) & $M$ & Use (\%) & $M$ & Use (\%) & $M$ & Use (\%) & $M$ & \\
\hline \multicolumn{10}{|l|}{ Primary health care } \\
\hline Medical visits & 100.0 & $89.8(42.1)$ & 100.0 & $84.1(38.9)^{\ddagger}$ & 100.0 & $81.5(26.5)^{\ddagger}$ & 100.0 & $83.6(54.2)$ & 0.013 \\
\hline Laboratory tests & 91.5 & $3.4(2.6)$ & 82.4 & $3.1(2.9)^{\ddagger}$ & 88.7 & $2.8(2.1)^{\dagger}$ & 85.6 & $3.1(2.6)$ & 0.001 \\
\hline Conventional radiology & 67.1 & $1.4(1.6)$ & 58.3 & $1.3(1.6)$ & 66.1 & $1.4(1.5)$ & 62.0 & $1.4(1.6)$ & NS \\
\hline Complementary tests & 40.4 & $0.6(0.9)$ & 37.1 & $0.7(\mathrm{I} .2)$ & 35.8 & $0.6(I . I)$ & 36.9 & $0.6(I . I)$ & NS \\
\hline \multicolumn{10}{|l|}{ Specialist health care } \\
\hline Days in hospital & 18.6 & $2.4(7.9)$ & 16.5 & $1.7(5.1)^{\ddagger}$ & 9.6 & I.I $(3.7)^{\dagger}$ & 15.2 & $\mathrm{I} .5(4.9)$ & $<0.001$ \\
\hline Medical visits & 90.1 & $13.1(10.6)$ & 85.6 & $11.7(12.4)^{\ddagger}$ & 91.4 & $10.5(10.6)^{\dagger}$ & 88.2 & II.4(II.6) & 0.002 \\
\hline Emergency services, visits & 51.6 & $2.2(3.2)$ & 52.7 & $1.5(2.7)^{\ddagger}$ & 58.4 & $1.3(1.9)^{\dagger}$ & 54.8 & $1.6(2.5)$ & $<0.001$ \\
\hline Sick leave (days) & 23.9 & $36.7(111.2)$ & 18.8 & $30.7(100.6)^{\ddagger}$ & 10.5 & $15.2(69.7)^{\dagger}$ & 15.9 & $25.2(91.3)$ & $<0.001$ \\
\hline
\end{tabular}

Notes: Values are expressed as mean (SD) or percentage; Use refers to the percentage of usage of resources among all the patients; $M$ refers to the mean for the use of the resources. ₹Statistically significant difference between smokers and ex-smokers; †'statistically significant difference between smokers and never smokers. Abbreviations: NS, not significant; SD, standard deviation. 
Table 3 Observed and adjusted costs $(€)$ model by study group

\begin{tabular}{|c|c|c|c|c|c|}
\hline \multirow{2}{*}{$\begin{array}{l}\text { Study group } \\
\text { Number of patients, } \%\end{array}$} & \multirow{2}{*}{$\frac{\text { Smoker }}{N=213(8.4 \%)}$} & \multirow{2}{*}{$\frac{\text { Ex-smoker }}{I, 344(52.9 \%)}$} & \multirow{2}{*}{$\frac{\text { Never smokers }}{N=983(38.7 \%)}$} & \multirow{2}{*}{$\frac{\text { Total }}{N=2,540(100.0 \%)}$} & \multirow[t]{2}{*}{$P$} \\
\hline & & & & & \\
\hline \multicolumn{6}{|l|}{ Unadjusted cost model } \\
\hline Health costs & $5,821.1(3,432.1)$ & $5,154.6(3,576.8)^{\ddagger}$ & $4,643.2(2,315.1)^{\dagger}$ & $5,012.6(3,153.2)$ & $<0.001$ \\
\hline Costs at primary health care level & $3,489.8(1,624.3)$ & $3,232.1(2,144.6)^{\ddagger}$ & $3,087.7(1,242.4)^{\dagger}$ & $3,197.8(1,806.3)$ & 0.008 \\
\hline Medical visits & $2,042.4(958.1)$ & $1,9 \mid 4.4(1,566.5)^{\ddagger}$ & $1,854.5(601.9)^{\dagger}$ & $1,901.9(1,231.8)$ & 0.013 \\
\hline Laboratory tests & $76.2(57.4)$ & $68.9(63.1)^{\ddagger}$ & $62.1(45.7)^{\dagger}$ & $66.9(56.6)$ & 0.001 \\
\hline Conventional radiology & $26.6(28.7)$ & $23.5(29.6)$ & $25.8(27.7)$ & $24.7(28.8)$ & NS \\
\hline Complementary tests & $22.1(33.5)$ & $24.4(44.1)$ & $21.6(40.3)$ & $23.1(4 I .9)$ & NS \\
\hline Medicines & $1,322.4(1,122.8)$ & $1,200.6(1,077.7)$ & $1,123.5(1,011.9)^{\dagger}$ & I,I8I.I $(1,057.8)$ & 0.028 \\
\hline Costs at specialist level & $2,331.2(2,759.3)$ & $1,922.6(2,142.6)^{\ddagger}$ & I,555.5 $(I, 663.7)^{\dagger}$ & I,8I4.7 (2,046.7) & $<0.001$ \\
\hline Days in hospital & $74 I .4(I, 487.3)$ & $532.5(I, 602.1)^{\ddagger}$ & $322.6(1,167.8)^{\dagger}$ & $468.8(1555.1)$ & $<0.001$ \\
\hline Medical visits & I,339.8 (I,088.9) & $1,206.3(1,271.1)^{\ddagger}$ & $1,072.5(1,086.8)^{\dagger}$ & I,I65.7 (I,190.4) & 0.002 \\
\hline Emergency services & $249.9(366.8)$ & $183.7(3 \mid 3.1)^{\ddagger}$ & $160.3(220.1)^{\dagger}$ & I80.2 (287.I) & $<0.001$ \\
\hline Non-health costs (productivity) & $2,006.9(5,078.7)$ & $\mathrm{I}, 677.8(5,500.3)^{\ddagger}$ & $832.3(3,807.1)^{\dagger}$ & I,378.2 (4,988.9) & $<0.001$ \\
\hline Total costs (health/non-health) & $7,828.0(6,766.3)$ & $6,832.4(6,672.8)^{\ddagger}$ & $5,475.5(4,586.9)^{\dagger}$ & $6,390.8(6,009.4)$ & $<0.001$ \\
\hline \multicolumn{6}{|l|}{ Adjusted cost model* } \\
\hline Health costs & $6,272.9$ & $5,672.5^{\ddagger}$ & $4,822.9^{\dagger}$ & - & $<0.001$ \\
\hline $95 \% \mathrm{Cl}$ & $5,656.3-6,889.5$ & $5,499.9-5,845.1$ & $4,630.1-5,015.7$ & & \\
\hline Costs at primary health care level & $3,941.0$ & $3,610.0^{\ddagger}$ & $3,225.6^{\dagger}$ & - & $<0.001$ \\
\hline $95 \% \mathrm{Cl}$ & $3,608.6-4,273.4$ & $3,516.9-3,703.1$ & $3,121.6-3,329.5$ & & \\
\hline Costs at specialist level & $2,332.0$ & $2,062.6^{\ddagger}$ & $1,597.3^{\dagger}$ & - & $<0.001$ \\
\hline $95 \% \mathrm{Cl}$ & $\mathrm{I}, 904 . \mathrm{I}-2,759.7$ & $1,942.8-2,182.2$ & I,463.5-I,73I.| & & \\
\hline Non-health costs (productivity) & $\mathrm{I}, 707.7$ & $1,649.6^{\ddagger}$ & $796.0^{+}$ & - & $<0.001$ \\
\hline $95 \% \mathrm{Cl}$ & $674.6-2,740.8$ & $\mathrm{I}, 360.4-1,938.7$ & $472.9-1,119.1$ & & \\
\hline Total costs (health/non-health) & $7,980.7$ & $7,322.1^{\ddagger}$ & $5,618.9^{\dagger}$ & - & $<0.001$ \\
\hline $95 \% \mathrm{Cl}$ & $6,725.7-9,235.6$ & $6,970.8-7,673.3$ & $5,226.5-6,011.2$ & & \\
\hline
\end{tabular}

Notes: Values are expressed as mean (SD); *ANCOVA Model: each F-test contrasts the simple effect of the presence in each combination of the rest of the effects shown. These verifications are based on linearly independent paired comparisons between the estimated marginal means. The covariables were: age, Charlson index, and RUBs; the fixed component was sex. ¥Statistically significant difference between smokers and ex-smokers; †statistically significant difference between smokers and never smokers.

Abbreviations: ANCOVA, analysis of covariance; $\mathrm{Cl}$, confidence interval; NS, not significant; RUB, resource usage band; SD, standard deviation.

\section{Author contributions}

All authors had complete access to the data and participated in the analysis and/or interpretation of results as well as the drafting and approval of the content of the manuscript. ASM, SDC, and VSB participated in the design and conceptualization of the original study and in the interpretation of data and the drafting the manuscript. RNA participated in the collection of data and interpretation of statistical analysis results, review of the manuscript, and made important contribution to several parts of the manuscript. All authors were responsible for literature review and extraction of references.

\section{Disclosure}

This study was sponsored by Pfizer SLU. Verónica Sanz de Burgoa is an employee of Pfizer SLU. Silvia DiazCerezo was a former employee of Pfizer SLU at the time of completion of the study and manuscript preparation. She is no longer working for Pfizer SLU. Antoni SicrasMainar was a paid consultant to Pfizer in connection with the development of this manuscript. The statistical analysis was performed by DataClinics and was funded by Pfizer SLU. The authors report no other conflicts of interest in this work.

\section{References}

1. World Health Organization: The European Report on Tobacco Control Policy. WHO European Ministerial Conference for a Tobacco-Free Europe. Warsaw: World Health Organization; 2002. Available at http:// www.euro.who.int/_data/assets/pdf_file/0016/68101/E77976.pdf. Accessed June 27, 2013.

2. Burns DM. Epidemiology of smoking-induced cardiovascular disease. Prog Cardiovasc Dis. 2003;46(1):11-29.

3. Boffetta P, Straif K. Use of smokeless tobacco and risk of myocardial infarction and stroke: systematic review with meta-analysis. $B M J$. 2009;339:b3060.

4. Banegas JR, Díez-Gañán L, González Enríquez J, Villar Alvarez F, Rodríguez-Artalejo F. La mortalidad atribuible al tabaquismo comienza a descender en España [Recent decrease in smoking-attributable mortality in Spain]. Med Clin (Barc). 2005;124(20):769-771. Spanish.

5. Marrugat J, Elosua R, Martí H. Epidemiología de la cardiopatía isquémica en España: estimación del número de casos y de las tendencias entre 1997 y 2005 [Epidemiology of ischaemic heart disease in Spain: estimation of the number of cases and trends from 1997 to 2005]. Rev Esp Cardiol. 2002;55(4):337-346. Spanish. 
6. Marrugat J, Sala J, Masiá R, et al. Mortality differences between men and women following first myocardial infarction. RESCATE Investigators. Recursos Empleados en el Síndrome Coronario Agudo y Tiempo de Espera. JAMA. 1998;280(16):1405-1409.

7. González-Enríquez J, Salvador-Llivina T, López-Nicolás A, et al. Morbilidad, mortalidad y costes sanitarios evitables mediante una estrategia de tratamiento del tabaquismo en España [The effects of implementing a smoking cessation intervention in Spain on morbidity, mortality and health care costs]. Gac Sanit. 2002;16(4):308-317. Spanish.

8. Critchley JA, Unal B. Is smokeless tobacco a risk factor for coronary heart disease? A systematic review of epidemiological studies. Eur J Cardiovasc Prev Rehabil. 2004;11(2):101-112.

9. Underner M, Perriot J, Sosner P, Herpin D. Snus et risque cardiovasculaire. [Smokeless tobacco and cardiovascular risk.] Ann Cardiol Angeiol (Paris). 2012;61(12):105-110. French.

10. Planas A, Clará A, Marrugat J, et al. Age at onset of smoking is an independent risk factor in peripheral artery disease development. J Vasc Surg. 2002;35(3):506-509.

11. van Berkel TF, Boersma H, Roos-Hesselink JW, Erdman RA, Simoons ML. Impact of smoking cessation and smoking interventions in patients with coronary heart disease. Eur Heart J. 1999;20(24): 1773-1782.

12. Nerín I, Novella P, Beamonte A, Gargallo P, Jiménez-Muro A, Marqueta A. Resultados del tratamiento del tabaquismo en una unidad especializada. [Results of smoking cessation therapy in a specialist unit.] Arch Bronconeumol. 2007;43(12):669-673. Spanish.

13. Jiménez-Ruiz CA, Barrueco Ferrero M, Solano Reina S, et al Recomendaciones en el abordaje diagnóstico y terapéutico del tabaquismo. Documento de consenso [Guidelines for a diagnostic and therapeutic approach to smoking addiction. A consensus report]. Arch Bronchoneumol. 2003;39(1):35-41. Spanish.

14. Lamberts H, Wood M, Hofmans-Okkes ÍM, editors. The Ínternational Classification of Primary Care in the European Community: With a Multi-Language Layer. Oxford: Oxford University Press; 1993.

15. Charlson ME, Pompei P, Ales KL, MacKenzie CR. A new method of classifying prognostic comorbidity in longitudinal studies: development and validation. J Chronic Dis. 1987;40:373-383.

16. Weiner JP, Starfield BH, Steinwachs DM, Mumford LM. Development and application of a population-oriented measure of ambulatory care case-mix. Med Care. 1991;29(5):452-472.

17. Instituto Nacional de Estadística. Encuesta Trimestral de Coste Laboral (ETCL). Tercer Trimestre de 2010. [National Statistics Institute. Quarterly Labour Cost Survey (QLCS), 2010] Madrid: Instituto Nacional de Estadística; 2010. Available from: http://www.ine.es/daco/daco42/ etcl/etc10310.pdf. Accessed June 8, 2013. Spanish.

18. Thompson SG, Barber JA. How should cost data in pragmatic randomised trials be analysed? BMJ. 2000;320(7243):1197-1200.

19. Ministerio de Sanidad y Consumo. Encuesta Nacional de salud de España 2006. [Ministry of Health and Consumer Affairs. Spanish National Health Survey, 2006] Madrid: Instituto Nacional de Estadística; 2006. Available from: http://www.msps.es/estadEstudios/estadisticas/ encuestaNacional/encuestaNac2006/EstilosVidaPorcentaje.pdf. Accessed June 8, 2013. Spanish.
20. Aziz O, Skapinakis $\mathrm{P}, \mathrm{Rahman} \mathrm{S}$, et al. Behavioural interventions for smoking cessation in patients hospitalised for a major cardiovascular event. Int J Cardiol. 2009;137(2):171-174.

21. Chow CK, Jolly S, Rao-Melacini P, Fox KA, Anand SS, Yusuf S. Association of diet, exercise, and smoking modification with risk of early cardiovascular events after acute coronary syndromes. Circulation. 2010;121(6):750-758.

22. Gellert C, Schöttker B, Brenner H. Smoking and all-cause mortality in older people: systematic review and meta-analysis. Arch Intern Med. 2012;172(11):837-844.

23. Eliasson B, Hjalmarson A, Kruse E, Landfeldt B, Westin A. Effect of smoking reduction and cessation on cardiovascular risk factors. Nicotine Tob Res. 2001;3(3):249-255.

24. Sienkiewicz-Jarosz H, Zatorski P, Witkowski G, Rogowski A, Scińska A, Ryglewicz D. Predyktory rzucania palenia po udarze mózgu. [Predictors of smoking cessation after stroke.] Neurol Neurochir Pol. 2010;44(2):181-187. Polish.

25. Janzon E, Hedblad B. Swedish snuff and incidence of cardiovascular disease. A population-based cohort study. BMC Cardiovasc Disord. 2009;9:21.

26. Asplund K. Smokeless tobacco and cardiovascular disease. Prog Cardiovasc Dis. 2003;45(5):383-394.

27. McRobbie H, Thornley S. La importancia de tratar la dependencia tabáquica. [The importance of treating tobacco dependence.] Rev Esp Cardiol. 2008;61(6):620-628. Spanish.

28. Yusuf S, Hawken S, Ounpuu S, et al; INTERHEART Study Investigators. Effect of potentially modifiable risk factors associated with myocardial infarction in 52 countries (the INTERHEART study): case-control study. Lancet. 2004;364(9438):937-952.

29. Teo KK, Ounpuu S, Hawken S, et al; INTERHEART Study Investigators. Tobacco use and risk of myocardial infarction in 52 countries in the INTERHEART study: a case-control study. Lancet. 2006;368(9536): 647-658.

30. Price JF, Mowbray PI, Lee AJ, Rumley A, Lowe GD, Fowkes FG. Relationship between smoking and cardiovascular risk factors in the development of peripheral arterial disease and coronary artery disease: Edinburgh Artery Study. Eur Heart J. 1999;20(5):344-353.

31. Kannel WB, Higgins M. Smoking and hypertension as predictors of cardiovascular risk in population studies. J Hypertens Suppl. 1990; 8(5):S3-S8

32. Lakier JB. Smoking and cardiovascular disease. Am J Med. 1992; 93(1A):8S-12S

33. Sicras-Mainar A, Navarro-Artieda R. Coste de la hipertensión arterial según grados de morbilidad en atención primaria [Cost of arterial hypertension according to levels of morbidity in primary care setting] Med Clin (Barc). 2009;133(8):290-295. Spanish.

\section{Dovepress}

\section{Publish your work in this journal}

ClinicoEconomics \& Outcomes Research is an international, peerreviewed open-access journal focusing on Health Technology Assessment, Pharmacoeconomics and Outcomes Research in the areas of diagnosis, medical devices, and clinical, surgical and pharmacological intervention. The economic impact of health policy and health systems

organization also constitute important areas of coverage. The manuscript management system is completely online and includes a very quick and fair peer-review system, which is all easy to use. Visit http://www.dovepress.com/testimonials.php to read real quotes from published authors. 